\title{
LINGUAGEM QUE GERA AFETIVIDADE: O USO DA MEDIAÇÃO PEDAGÓGICA VIA WHATSAPP COMO ESTRATÉGIA DE ACOMPANHAMENTO DE ALUNOS NA DISCIPLINA DE METODOLOGIA DO TRABALHO CIENTÍFICO A DISTÂNCIA DO IPOG
}

GOIÂNIA/GO MAIO/2018

\author{
Ariana Ramos Massensini - IPOG - ariana.senai@gmail.com \\ Deivid Mendes de Sousa Borges - IPOG - deividmendesprofessor@gmail.com \\ Tipo: Relato de Experiência Inovadora (EI) \\ Categoria: Métodos e Tecnologias \\ Setor Educacional: EDUCAÇÃO SUPERIOR
}

\section{RESUMO}

Este trabalho relata a experiência do IPOG com a utilização de estratégias de acompanhamento da disciplina de Metologia do Trabalho Científico (MTC), realizada na modalidade a distância, que fazem uso de peças construídas com base na dimensão afetiva da linguagem. A base teórica para a mediação pedagógica e afetividade se pautou nos estudos de Vygotsky (2000, 2003). Os procedimentos utilizados incluíram: análise dos feedbacks dados pelos alunos no momento que recebem as peças, via WhatsApp e dos indíces de satisfação e conclusão da disciplina medidos por meio da Ficha de Avaliação. Os resultados evidenciaram maior engajamento, satisfação e aumento do percentual de conclusão nas turmas em que essa estratégia foi aplicada.

Palavras-chave: Educação a Distância, afetividade, estratégia de acompanhamento. 


\section{Introdução}

A Educação a Distância possibilita a criação de um novo cenário para a formação docente. Segundo Prado (2006), a mediação pedagógica, na abordagem do estar junto virtual, se concretiza pelas constantes recriações de estratégias durante a realização de um curso, a partir da inter-relação dos materiais, atividades e interações. As emoções, então, aparecem através da mediação pedagógica que ocorre dentro da sala de aula online e em outras ferramentas utilizadas no processo de comunicação que ocorre em um curso a distância.

Galvão (2003) diz que "o recurso da fala e das representações mentais faz com que variações nas disposições afetivas possam ser provocadas por situações abstratas e ideias, e possam ser expressas por palavras" (p.76). O autor ainda segue dizendo que "uma atividade situada entre o orgânico e o social, a emoção tem seus efeitos fortemente determinada pela acolhida que lhe é dada. Desde os primórdios até idades mais avançadas, a emoção se nutre do efeito que causa no outro" (GALVÃO, 2003, p. 77).

A partir desse pensamento, conclui-se, então, que a linguagem desperta a consciência e forma o pensamento humano. Vigotsky (2001) defende a linguagem como prática social, levando em consideração a imaginação, memória e organização. A concepção de mediação pedagógica e afetividade tratada aqui parte dos estudos de Vygotsky (2000), concebida como um processo de intervenção de um elemento intermediário na relação entre o sujeito e o mundo.

O objetivo deste trabalho, portanto, é relatar a experiência do Instituto de PósGraduação e Graduação (IPOG) durante a utilização de estratégias de acompanhamento da disciplina de Metologia do Trabalho Científico (MTC), realizada na modalidade a distância, que fazem uso de peças construídas com base na dimensão afetiva da linguagem. Os resultados evidenciaram maior engajamento, satisfação e aumento do percentual de conclusão nas turmas em que essa estratégia foi aplicada.

\section{Referencial teórico}

\subsection{O que é mediação pedagógica e afetividade?}

A mediação pedagógica é um conceito fundamental para a compreensão dos processos 
de aprendizagem e de desenvolvimento humano, visto que é por meio de um intenso processo de interação com o meio social, através da mediação feita pelo outro, que os sujeitos se apropriam dos objetos culturais e se desenvolvem (VYGOTSKY, 2000).

As interações presentes nos Ambientes Virtuais de Aprendizagem (AVA), de acordo com Kenski (2003), "podem ser unidirecionais, sem maiores trocas comunicativas. Em termos de uso das tecnologias digitais para fins didáticos, colocar o programa do curso, os textos a serem lidos ou os exercícios, na Internet, para acesso e conhecimento de todos os alunos, seria um possível nível interativo elementar" (p.123).

Apesar do AVA apresentar, em sua maioria, estruturações padronizadas e/ou parecidas, a forma com que o conteúdo das disciplinas é conduzido se configura como individual, já que cada professor faz a mediação do seu jeito.

Nesse sentido, a nossa base teórica partiu dos estudos de Vygotsky (2000), segundo esse autor "o pensamento tem sua origem na esfera da motivação, a qual inclui inclinações, necessidades, 4 interesses, impulsos, afeto e emoção" (p.6-7).

contexto educativo envolve comportamentos que carregam crenças, vontades e interesses, e tais comportamentos afetam as interações entre as pessoas e geram sentimentos de prazer e desprazer que podem favorecer ou não o processo de ensinar e de aprender (FREIRE, 2011). Nesse sentido, pode-se dizer que:

toda experiência de aprendizagem se inicia com uma experiência afetiva. É a fome que põe em funcionamento o aparelho pensador. Fome é afeto. O pensamento nasce do afeto, nasce da fome. Não confundir afeto com beijinhos e carinhos. Afeto, do latim "affetare", quer dizer "ir atrás". É o movimento da alma na busca do objeto de sua fome. É o Eros platônico, a fome que faz a alma voar em busca do fruto sonhado (ALVES, 2002, p. 1).

\section{A experiência do IPOG}

A história do IPOG é pautada no sucesso e no êxito em especializar profissionais. Sua implantação teve início no ano de 2001, na cidade de Goiânia (GO), para atender às demandas de cursos de pós-graduação, aperfeiçoamento e capacitação profissional. Atualmente, o IPOG está presente em todos os estados do Brasil e no Distrito Federal, o que comprova o crescimento do Instituto em um segmento de mercado altamente competitivo e que exige modernizações e inovações constantes. 
A experiência com a formatação de produtos de Educação a Distância e atendimento de alunos em disciplinas semipresenciais, teve início no ano de 2014, com a efetiva produção e oferta da disciplina de MTC, aplicada na Pós-graduação lato sensu. Todos os alunos matriculados desde então, nos cursos de pós-graduação presenciais, cursam essa disciplina na modalidade a distância.

\subsection{Oferta da disciplina de Metodologia do Trabalho Científico a distância}

A disciplina de MTC é disponibilizada para uma turma a partir do $10^{\circ}$ módulo cursado de uma pós-graduação. Esse momento representa cerca de 50\% do andamento do curso. A partir da data de liberação, o conteúdo fica disponível para estudo por 30 dias.

Nesse período, os alunos são acompanhados pela equipe de tutoria, que se reporta ao professor da disciplina, e precisam acessar os conteúdos, assistir às videoaulas e realizar atividades avaliativas.

A disciplina é composta por e-book interativo, videoaulas, livro didático, materiais de apoio (artigos de revistas científicas, conteúdos sobre plágio, sugestões de temas para a produção do TCC, dentre outros). É disponibilizado, para os alunos, um template com o modelo do artigo trabalhado pelo IPOG.

O acesso ao conteúdo é realizado por meio do AVA Moodle. Ao final dos estudos, os alunos são convidados a preencher uma ficha de avaliação da disciplina. Esse instrumento permite uma avaliação das seguintes dimensões: tutoria, infraestrutura virtual, organização da disciplina, além de uma autoavaliação. Os resultados são utilizados como filtro para implementação de ações de melhorias.

A figura 1 apresenta a organização da disciplina no AVA. A forma de comunicação, tanto verbal quanto não verbal, foi evoluindo ao longo dos 4 anos de oferta da disciplina. Os elementos são trabalhados de forma lúdica, favorecendo a compreensão da estruturação de cada uma das seções que compõem o ambiente.

Figura 1 - Organização da disciplina de MTC a distância 


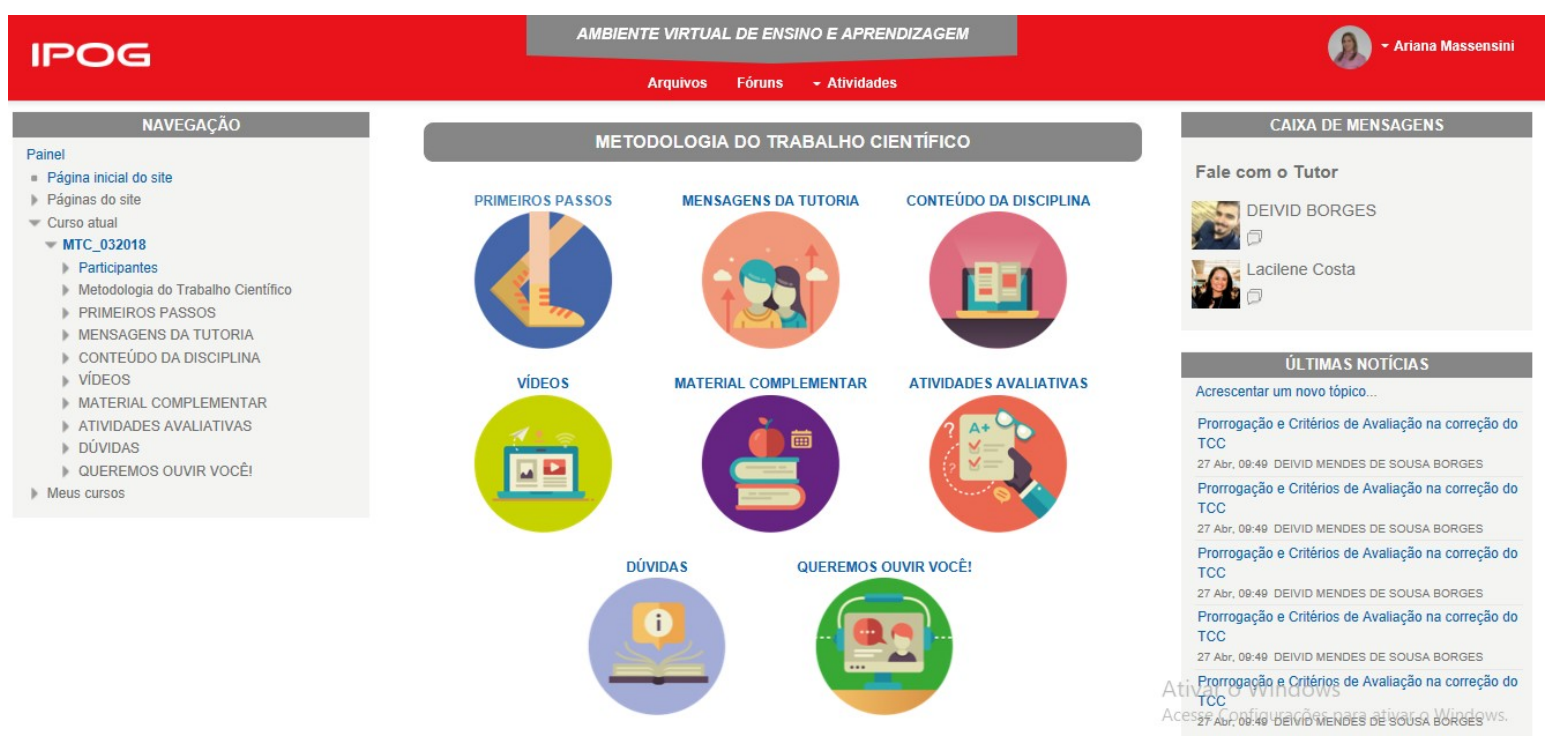

Fonte: (IPOG, 2018).

\subsection{Estratégias de acompanhamento}

Embora a disciplina de MTC seja obrigatória para a conclusão dos cursos de pósgraduação no IPOG, os resultados revelam um alto percentual de alunos que não a realizam no tempo estipulado em cronograma. Essa situação acarreta taxas de reposição para dar o direito ao aluno de cursar a disciplina novamente.

A comunicação com os alunos antes, durante e depois da realização da disciplina é feita por meio de ferramentas do AVA, e-mail e telefone. No discurso que compõe as mensagens do curso, além de um caráter motivacional e personalizado, a equipe de tutoria procura dar um enfoque prático para a disciplina.

Objetivando aumentar o índice de participação, engajamento e satisfação dos alunos na disciplina, em 2018, a equipe de educação a distância começou a utilizar peças e gifs, considerando a dimensão afetiva da linguagem como principal foco, durante o acompanhamento dos alunos.

Essas peças e gifs são enviados semanalmente, conforme um cronograma previamente estruturado, por e-mail ou WhatsApp. As peças produzidas com o apoio da área de marketing possuem 3 objetivos: reconhecer os alunos que estão com os estudos em dia (criando um clima favorável para a manutenção do relacionamento com turma); despertar o interesse do aluno que está com o conteúdo atrasado e/ou que nunca o acessaram; e apresentar dicas essenciais que apoiarão os alunos quando estiverem 
desenvolvendo o trabalho de conclusão de curso. A seguir, apresentaremos modelos de peças utilizados.

Figura 2 - Exemplo de peça enviada para alunos em atraso ou que não acessam o AVA por mais de uma semana

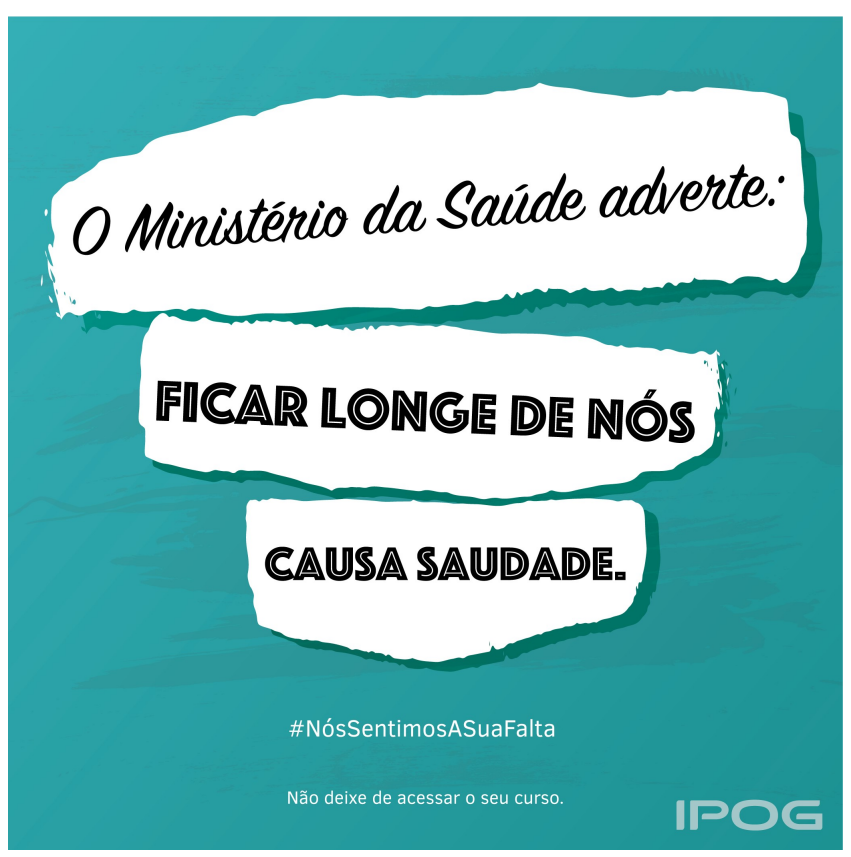

Fonte: (IPOG, 2018).

Figura 3 - Exemplo de peça enviada para alunos que estão com o cronograma de estudos em dia 


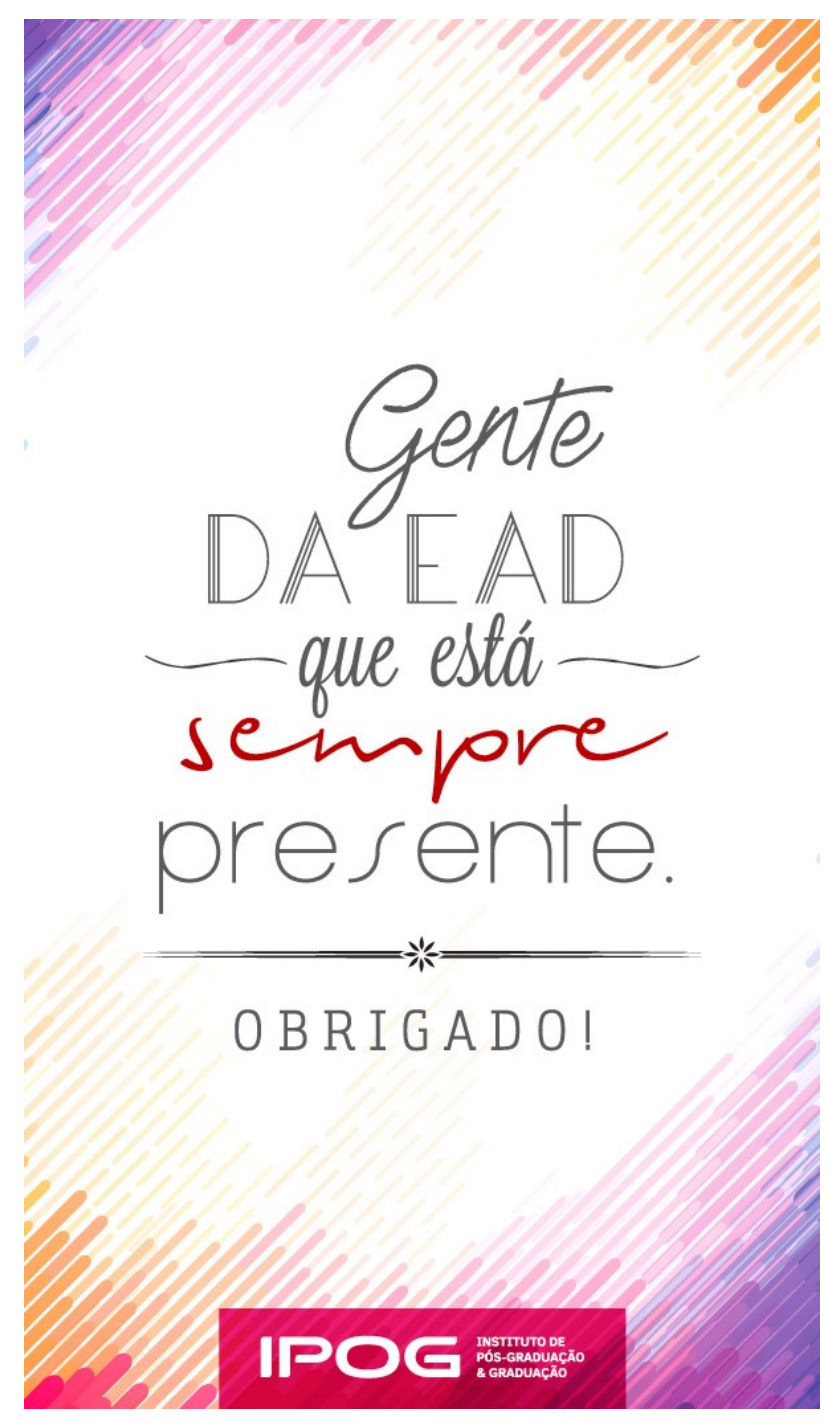

Fonte: (IPOG, 2018).

Figura 4 - Dicas para a produção do TCC 


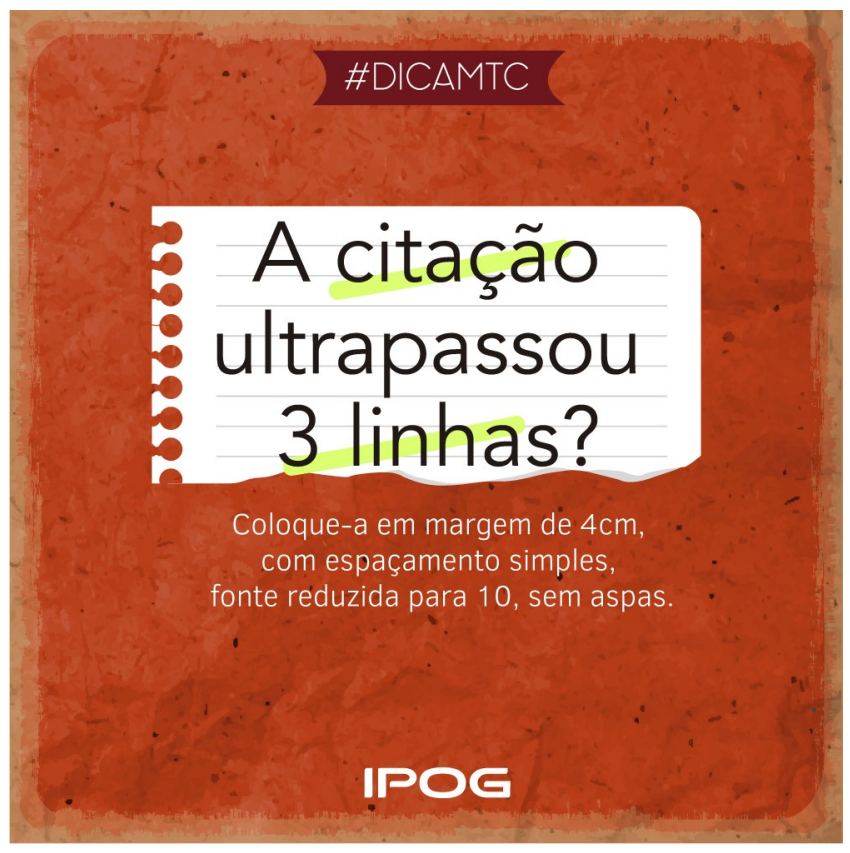

Fonte: (IPOG, 2018).

\section{Resultados}

Foi possível constatar, ao analisar os resultados das turmas atendidas no primeiro trimestre de 2018 e comparar com o mesmo período de 2017, o aumento na média de satisfação dos alunos com o desenvolvimento da disciplina de MTC. Esse resultado foi apurado por meio da ficha de avaliação presente no final da disciplina.

No primeiro trimestre de 2017, a média de satisfação com a disciplina ficou em 87,29\%. Já no primeiro trimestre de 2018, a média de satisfação alcançou 90,50\%.

Foi possível perceber um aumento significativo também no percentual de concluintes. No primeiro trimestre de 2017 , o percentual de conclusão foi de $77,05 \%$. No mesmo período de 2018, o percentual de conclusão aumentou para $81,14 \%$.

Quanto aos dados qualitativos, houveram, também, manifestações verbais por parte dos alunos em relação às estratégias utilizadas no desenvolvimento da disciplina. Alguns exemplos de feedbacks estão expressos abaixo:

Aluno 1: Foi excelente o envio de mensagens via whatsapp com dicas sobre o TCC, o que, além de transmitir conhecimento, me fez lembrar da necessidade de atender ao módulo.

Aluno 2: Boa iniciativa! Esse é o diferencial do IPOG. 
Aluno 3:Muito boa a dica, pode mandar outras dicas. Amei! É por isso que o IPOG está onde está.

É importante destacar que a maiorias desses relatos verbais foram realizados via WhatsApp e também postados no ambiente virtual da disciplina.

\section{Conclusões}

Uma proposta pedagógica educacional de cursos a distância, para ser bem-sucedida, precisa ter como foco alunos e educadores, independente da tecnologia escolhida. É preciso aprender a desenvolver estratégias diferentes para situações de aprendizagem diferentes. A mediação pedagógica e a afetividade estão revolucionando o processo de ensino e aprendizagem. São pontos de partida para avançar para processos de reflexão mais complexos.

Nesse sentido, conclui-se que é fundamental ficar atento à linguagem utilizada no AVA, mas também investir em contatos "extras", pois é necessário fazer uso de comunicações agradáveis e acolhedoras que favorecem o ensino-aprendizagem como é o caso das peças e gifs.

Assim sendo, é essencial que a linguagem científica não apareça como imposição, isto é, como única e absoluta, pois isso pode fazer com que o aluno veja esse tipo de linguagem como não entendido ou significado.

Segundo Kenski (2000), "a evolução humana acompanha a evolução não apenas da linguagem, mas, também, das tecnologias que a suportam e a processam; A linguagem falada e a escrita são as primeiras tecnologias da inteligência - ou da linguagem".

"No que se refere à afetividade, os seres humanos são capazes de emoções mais sofisticadas em relação aos animais porque dispõem de um equipamento específico da espécie que define um modo de funcionamento psicológico essencialmente mediado. Com o papel primordial da linguagem e a importância da interação social para o desenvolvimento pleno dos indivíduos, os seres humanos operam com base em conceitos culturalmente construídos que constituem, representam e expressam não só seus pensamentos, mas também suas emoções" (KOHL; REGO, 2003, p. 25). 
ALVES, RUBENS. A arte de produzir fome. Disponível em: < http://www6.ensp.fiocruz.br/visa/files/Texto_Rubens\%20Alves_A\%20arte\%20de\%20prod uzir\%20fome.pdf>. Acesso em: 30/08/2017. .

FREIRE, Paulo. Pedagogia da autonomia: saberes necessários à prática educativa. 43. ed., São Paulo: Paz e Terra, 2011.

GALVAO, Izabel. Expressividade e emoções segundo a perspectiva de Wallon. In: ARANTES, Valéria Amorim. Afetividade na escola: alternativas teóricas e práticas. São Paulo: Summus, 2003.

KENSKI, V.M. Tecnologias e ensino presencial e a distância. Campinas, SP: Papirus, 2003.

KOHL, Marta de O.; REGO, Teresa Cristina. Vygotsky e as complexas relações entre cognição e afeto. In: ARANTES, Valéria Amorim. Afetividade na escola: alternativas teóricas e práticas. São Paulo: Summus, 2003.

PRADO, M.E.B.B. A mediação pedagógica: suas relações e interdependências. In: VALENTE, J. A. (org.) Formação de professores para o uso da informática na Escola. Campinas - SP: UNICAMP/NIED, 2003.

VYGOTSKY, L. S. 2 ed. São Paulo: Martins Fontes, 2000, 194 p. Trabalho original publicado em 1934.

VYGOTSKY, L.S. Psicologia pedagógica. Tradução Paula Bezerra. São Paulo: Martins Fontes, 2001. 